\title{
EVALUATION OF ENGINEERING TRAINING COMPETENCES IN THE FIELD OF SMART SYSTEMS AS A FACTOR OF RUSSIAN INNOVATIVE DEVELOPMENT THROUGH THE EXAMPLE OF TOMSK POLYTECHNIC UNIVERSITY
}

\author{
Igor B. Ardashkin ${ }^{1, *}$, and Ekaterina A. Kirsanova ${ }^{1}$ \\ ${ }^{1}$ Tomsk Polytechnic University, 634050, Tomsk, Russia
}

\begin{abstract}
The article dwells on Russian system of educational engineering training in the field of smart systems with a view to its innovative component through the example of National Research Tomsk Polytechnic University (TPU). The article highlights that the development of innovations has two significant components (technological-economic and social-humanistic). It is proved that only with equal combination of these two components in innovations it is possible to obtain maximum innovative development effect for economy of any country. It is concluded that the system of educational engineering training in TPU is misbalanced in terms of innovative development due to considerable technologicaleconomic component dominance over social-humanistic one. The authors propose possible ways to overcome this misbalance of innovative development in the system of engineering education of TPU upgrading event block on staff and students motivational competences improvement.
\end{abstract}

\section{Introduction}

Smart systems are such systems which even being technologically sophisticated (with cutting-edge technologies and advanced equipment) will not run without such components as cultural, social, economic and organizational. Their main task is to use technical systems as close as possible to human capacities and at the same time to exclude human participation in their functioning to the greatest possible extent. Their application is of universal nature and presupposes the ability of usage in highly expanded range of social areas of human life. But these systems will work only when society will understand the necessity of such developments and follow the rules of its application.

As a consequence, the appropriate system of educational training is needed for innovative economy as well as for the development and implementation of Smart systems.

\footnotetext{
${ }^{*}$ Corresponding author: ibardashkin@,tpu.ru
} 
As a result, the main purpose of the article is to evaluate present educational programs of engineering training (main competences as indicators of their effectiveness) through the example of Tomsk Polytechnic University with a view to their innovative component.

\section{Results and discussion}

National Research Tomsk Polytechnic University (TPU) is the first engineering university founded in Asian part of Russia, which has a great experience of training engineers. Currently according to internal ratings TPU is one of the leading Russian technical universities beyond Moscow and St. Petersburg [1]. It is necessary to clarify certain concepts before starting the evaluation of competencies of engineering education in the field of Smart systems as a factor of innovative development of Russia through the example of TPU.

In particular, it refers to such concepts as innovation, innovative development, innovativeness. It is important in order to clarify the topic of discussion and show the connection between educational engineering training, Smart systems, innovations and innovative development.

When Joseph Schumpeter in his "Theory of Economic Development" used the concept of "innovation", he wanted to emphasize the difference between the concepts of economic growth and economic development. The concept of "innovation", according to Schumpeter, is important to demonstrate the qualitative difference in the implementation of a process, in the functioning of a phenomenon. Schumpeter expressed five types of qualitative changes, demonstrating the nature of innovation [2].

Another author Peter Drucker believed that innovation is a characteristic of human mentality and his ability to control his own destiny and the destiny of individuals, organizations and enterprises. Innovation according to P. Drucker is not necessarily a characteristic of commercial entity, it can be used in the non-profit sector. P. Drucker wants to emphasize social and humanistic aspect of any innovation, illustrating such important components of innovation and innovative development as: the opportunity for human selfrealization, tuning into creation and introduction of something new; the importance of social contacts, allowing to capture the mood and the needs of the present society, realizing them in the form of innovation (it would be much more difficult to make it in the situation of closed nature); technological component through which innovation is implemented and used; economic component aimed at keeping financial and any other efficiency innovations [3].

Thus, Peter Drucker wants to emphasize that technological characteristics of innovation alone (new technology, profit, organizational transformations) cannot be regarded as a significant indicator of innovative development, as we can often find in publications and speeches of local researchers, administrative officers, etc. Humanistic and social components of innovation, drawing on the understanding of Schumpeter, allow making some qualitative transformations in current changes, turning economic growth into economic development.

Nowadays this aspect is especially significant because the evaluation of innovative development of countries, enterprises, business vehicles and universities can differ widely. This difference can be seen very clearly in various ratings of innovative development of countries all over world. It is necessary to clarify that the differences in evaluation are mainly related to the coverage of basic innovation components: technological, economic, social and humanistic. Let us demonstrate this with the help of two ratings of global innovative development evaluation: The Global Innovation Index formed by World Intellectual Property Organization (WIPO) magazine in cooperation with Cornell University (USA) according to the methodology of STEAD Business School (France) and 
The Bloomberg innovation index. According to these ratings for the previous 2015 year Russia ranked 49 and 14 positions for the development of innovation among other countries of the world. Taking into consideration that the difference between these positions is considerable, it can be concluded that different methods of calculation were used, since in one case we are talking about averages, and in the other case we are talking about the position, displaying relatively high levels of innovation.

In the rating of Global Innovation Index the methodology takes into account two groups of indicators: the resources and conditions for innovation (institutions, human capital and research, infrastructure, development of internal market; business development) and present practical results of innovation (technology development and the knowledge economy; the results of creative activity).

The Bloomberg innovation index methodology is based on 7 criteria: Research and Development intensity, productivity, concentration of high technology, concentration of research, production capacity, and efficiency of tertiary and patent activity.

If we compare these two ratings on the criteria of evaluation, it appears that innovation Bloomberg index rating is more of technological and economic nature, whereas the Global Innovation Index seeks tries to take into account socio-humanistic component of innovative development. Such criteria as institutions, human capital, infrastructure, results of creative activity, etc. involve not only technological and economic characteristics, but also the evaluation of conditions, relationships, human activity, which means that social and humanistic component of innovation, is taken into consideration.

If we refer to the experience of Tomsk Polytechnic University (TPU), it is possible to detect similar trends and in its functioning.

Innovative component is the most important trajectory of development of the University because the goal of the University is the establishment and development of TPU as a research university - one of the world leaders in the field of resource efficient technologies that solve the global problems of humanity on the path to sustainable development [4]. This goal is unreachable without innovative filling. The University makes great effort in the indicated direction. This also can be applied in educational and research component.

The emphasis is laid on innovative component of educational training. In recent years, curricula were annually adjusted, taking into account wishes of students and prospective employers with whom the leaders of main educational programs are trying to cooperate. These changes can be tracked through the documentation on educational areas of training in the last 5 years on the University website in "Education programs fund of TPU" and "Education" sections.

At different levels of training special emphasis is laid on the development of creative abilities, independence and initiative. In absolutely all areas of training the University provides teaching and research work, creative project - specific discipline in which students learn to carry out research. In addition, in each of the disciplines, which students learn, there is a focus on project-based approach, which allows not only absorbing some information and knowledge, but also producing their own information and learning how to use it for practical purposes.

The course "Creative workshop for engineers", which allows not only identifying the degree of human creativity, but also managing the development of creative abilities is introduced as an elective course for the development of creative and heuristic competences at the undergraduate level [5]. The course of "Scientific fundraising" is introduced as an elective one at the graduate level allowing undergraduates not only to learn how to organize, to conduct and to protect their own projects, but also to practically implement, simultaneously learning and getting adequate support from various funds. 
By analogy, we can consider the scientific component. As a rule, an innovative trajectory of the University is expressed in the creation of innovative infrastructure of universities around the enterprises established with the participation of teachers, students, business representatives (the most famous zone of such enterprises - Silicon Valley at Stanford University in the US. Tomsk Polytechnic University has its own business incubator - a place which is specially designed for start-ups at the interface of science and business. This place has several small innovative enterprises, where active organizers implement and sell innovative developments. Only on the website of the University it is indicated 47 enterprises [6]. It is enough for half a million population of Tomsk, where there are five large state universities apart from TPU. Here is a list of products and services that they can provide to potential customers. This also is not the whole list of scientific events of innovative type, but it gives an understanding of the seriousness of the consideration of the University.

There are seven main reasons preventing successful innovative development of Tomsk Polytechnic University: not enough level of English proficiency of students and staff; low level of internationalization; concentration of "big" science in state academies; orientation of a substantial part of successful school graduates to capital universities; a small number of educational programs in English; infrastructure of the campus is not modern enough; "Technological stagnation" of 90s in Russia, accompanied by law demand for the engineering profession; barriers complicating the employment of foreign scientists in Russian universities [7]. Among these reasons, only two of them are caused by technological and economic aspects: insufficient infrastructure of the campus and "technological stagnation" of 90s in Russia, accompanied by law demand for the engineering profession. The last reason is hardly included, as law demand for engineering profession - is the cause of social and humanistic nature. All other reasons related to sociohumanistic field and may be grouped as follows: the lack of qualified staff and the lack of employee motivation. It should be added that usually a lack of qualified personnel is a consequence of a lack of motivation. Motivation sphere - is a very "sophisticated" area which cannot be controlled by any quantitative indicators.

Smart systems act as a result of such activities, which let us estimate the completeness of representation of all aspects of developing innovations (technological and economic, social and humanistic). Only relatively equivalent representation of designated aspects of innovation enables successful development and application of any smart system. The fact that Tomsk Polytechnic University addresses to such systems as Smart Grid shows the correctness of chosen trajectory of innovative development, another thing is that without the emphasis on socio-humanistic aspect this development will be severely constrained and stopped. It was stated earlier by the authors $[5,8,9,10]$.

\section{Conclusion}

To conclude with, it is necessary to say that the evaluation of educational system of engineering training competencies in TPU (as well as in Russia as a whole) in the field of Smart systems is uneven, due to the fact that the technological and economic aspect are predominant in innovative development. It is expressed through the development and use of new technologies and products focus on commercial exploitation of innovations created in university. As a result, technical and economic success is neutralized by the fact that it does not lead to corresponding social transformation in minds and behavior of people, and therefore does not lead to effective use of development of society (e.g., the acquisition of modern medical equipment initiated by Russian government program did not improve the quality of health services in most cases, because the equipment was never used and was left in warehouses). Reconstruction of the balance between technological and economic, social 
and humanistic aspects of innovative development is the only trajectory to improve the quality of educational programs of TPU and other higher education institutions of Russian Federation, as well as the quality of life of our population. But to do this it is important to implement the restructuring of motivational aspects of university employee's activity, where corporate culture can become the most convenient tool.

The research is conducted with the financial support from Russian Humanitarian Science Foundation 16-16-70006

\section{References}

1. Reyting TPU [Online] http://tpu.ru/today/facts-numbers/ratings/

2. J. A. Schumpeter. Teoriya economicheskogo razvitiya, Capitalizm, socialism I democratiya (ECSPO, Moscow, 2007) [in Russia]

3. P. Drucker, Management Challenges for the 21st Century (Taylor \& Francis Ltd., New York, 2001)

4. Plan meropriyatiy po realizatsii Programmy povesheniya konkurentosposobnosti ("dorozhnaya karta") federalnogo gosudarstvennogo avtonomnogo uchrezhdeniya vysshego obrazovaniya "Nationalnyy issledovatelskiy Tomskiy politechnicheskiy universitet" na 2013-2020 gody (2 etap - 2015-2016 gody) (Moscow, 2015) URL: http://tpu.ru/f/2365/dk 2015.pdf

5. I. Ardashkin, L. Korobeynikova, A. Popova, Status of social competencies of power engineers in the context of forming the concept of an intelligent network or smart grid, MATEC Web of Conf. 37, 01003 (2015)

6. Malye innovazhionnye predpriyatiya. Corporativnyy portal Tomskogo politechnicheskogo universiteta (Tomsk, 2016) [Online] http://portal.tpu.ru/departments/otdel/bi/mip

7. Programmy povysheniya konkurentosposobnosti. Sayt TPU (Tomsk, 2016) URL: http://tpu.ru/today/today/programs/viu/

8. A. Chmykhalo, V. Khaliulina, M. Abushaeva, Innovative Power Systems and The Formation of The Creative Class in Russia, MATEC Web of Conf. 37, 01016 (2015)

9. M. Makienko, N. Kurkan, A. Strelcowa, Philosophical approach to engineering education under the introduction of the smart grid concept in Russia, MATEC Web of Conf. 37, 01031 (2015)

10. I. Ardashkin, A. Bykov, E. Kirsanova, The status of world outlook and environmental competencies in aerospace engineering training: the general and special, MATEC Web of Conf. 48, 06004 (2016) 